\title{
MANUAL ASSEMBLY LINE OPERATOR SCHEDULING USING HIERARCHICAL PREFERENCE AGGREGATION
}

\author{
Gonca Altuger \\ Constantin Chassapis \\ Department of Mechanical Engineering \\ Stevens Institute of Technology \\ Castle Point on Hudson \\ Hoboken, NJ, 07030, USA
}

\begin{abstract}
Successful companies are the ones that can compete in the global market by embracing technological advancements, employing the lean principles, maximizing resource utilizations without sacrificing customer satisfaction. Lean principles are widely applied in semi or fully automated production processes. This research highlights the application of the lean principles to manual assembly processes, where the operator characteristics are considered as deterministic of operator schedule. In this study, a manual circuit breaker assembly line is examined, where operator skill levels, attention spans, classified as reliability measures considered to select the most suitable resource allocation and break schedules. The effect of operator attributes on the process is modeled and simulated using Arena, followed by a hierarchical preference aggregation technique as the decision making tool. This paper provides an operator schedule selection approach which can be both employed in manual and semi - automated production processes.
\end{abstract}

\section{INTRODUCTION}

Success of a production process can be constrained by several factors such as; machine availabilities, production deadlines, operator skill levels and machine break-downs. Companies may need to consider constant tradeoffs between missing production deadlines and paying overtime when constrained by such factors, these kind of tradeoffs might seen as an indicator of an ill-utilized production process. Production process utilization can be maximized through waste reduction, planning and scheduling. In their study Govil and Magrab (2000) emphasized that production computations should always include scheduling of the operations. Adams et. al (1999) highlighted the wastes of manufacturing as; producing more product than needed, waste of inventory, waiting, waste of motion, waste of transportation and waste of processing. Lean principles can be applied to reduce such waste. One way to eliminate waste is to detect and remove the bottlenecks in a production process; Faget, Eriksson and Herrmann (2005) presented a successful bottleneck detection method in discrete event models developed by Toyota Motor Company. Another way of eliminating waste is to implement production plans; Fixson (2004) suggested that it is crucial to plan the life cycle of products to eliminate costs which might cause producing more products than needed. One other widely used way of waste elimination is to implement schedules that maximize the production rates, minimize downtimes and waiting. The implementation of such production schedules not only considers the machine schedules, but also the maintenance and operator assignment schedules. Chong, Sivakumar and Gay (2003) presented a simulation-based real-time scheduling mechanism to deal with the changes in a dynamic discrete manufacturing system. In order to have an effective understanding of the expectations from a production line. Venkateswaran, Son and Jones (2004) proposed a hierarchical production planning approach that provides a formal bridge between long-term plans and shortterm schedules. 


\section{Altuger and Chassapis}

Properly modeling a production line not only involves scheduling of the machines but also includes the scheduling of the operators, since the operator characteristics will have as strong effect on the outcome as the machine characteristics. Seppanen (2005) examined an Arena-based operator-paced assembly line simulation, that considers the movement of operators between cells and intermittent duties such as equipment repair and material handling. In their study Cassady and Kutanoglu (2003) proposed an integrated model that simultaneously determines production scheduling and preventive maintenance planning decisions so that the total weighted tardiness of jobs is minimized. Yang et. al (2007) highlighted the importance of maintenance scheduling and prioritization and presented a metric that can be used to quantitatively evaluate the effects of different maintenance priorities. Altuger and Chassapis (2009b) performed a case study based multi criteria decision-making analysis in their research to select the most appropriate maintenance technique and schedule for an automated packaging line. Altuger and Chassapis (2009a) proposed a hierarchical decision-making approach, where they benefited from simulation outcomes to support their decision-making process.

When evaluating maintenance and operator schedules, researchers depend on the use of simulations to understand the process behavior and to benefit from simulation outcomes in their decision-making process. McLean and Shao (2003) confirmed that manufacturing managers typically commission simulation case studies to support their decision-making process; therefore it is important to have simulation models that are realistic. When building a simulation model for an automated production line and manual production line, one needs to account for different parameters, since automated production lines and manual production lines differ from each other in terms of how their reliability levels change over time. Machines' reliability levels decrease as they work on repetitive tasks where they are bound to fail eventually, whereas humans get better at their task as they repeat it. Humans however cannot carry a sustained attention span through an 8 hour shift, which causes them to lose focus and result in higher faulty parts, therefore it is important to schedule adequate breaks to provide them with the needed rest time. Bevis, Finniear and Towill (1970) investigated the operator performance during learning of repetitive tasks, and proposed a Taylor series technique for predictions of the exponential learning law. Hackett (1983) compared various methods and concluded that Bevis' model provided the most practical model when measuring learning curve on repetitive tasks. Jaber and Bonney (1996) looked at the forgetting aspect as well as the learning aspect, and investigated if the operators suffer from forgetting phenomena during production breaks and r-learn in their shift time, and developed a learn-forget curve model to predict production outcomes. Shafer, Nembhard and Uzumeri (2001) examined the effects of worker learning and forgetting on assembly line productivity.

In this study a manual circuit breaker assembly line will be examined as a case study, where operator behaviors, attention spans, etc., are related to reliability/failure rates, and the process outcomes will be monitored though line simulation. The objective of this study is to select the most appropriate operator break schedule considering the operators' attention span, expertise and reliability which result in blocked and starved times, workstation utilization, average output factor, and cost. The selection process will be performed employing a hierarchical decision-making technique, where the weight values will be assigned based on simulation outcomes and hierarchical rankings. Throughout this effort, the considered case study is modeled using Arena's packaging template, where operator attention spans, break needs, shift schedules, reliability levels and line outcomes can be modeled, simulated and production outputs can be monitored.

\section{MANUAL ASSEMBLY LINE OPERATOR SCHEDULE SET - UP PROCESS}

\subsection{Circuit - Breaker Manual Assembly Line}

A circuit breaker consist of several components as shown in Figure 1 and the assembly process is a manual assembly line that consists of serially connected stations, as shown in Figure 2. The trip units and molded casings arrive at the sub assembly station, where operator 1 is located. Once the sub assembly is 


\section{Altuger and Chassapis}

completed, it gets moved to the mechanical sub assembly station to operator 2 to get assembled with barrier units to form the mechanical sub assembly. The mechanical sub assemblies are then moved to operator 3, where they are assembled with the chutes to form the arc chute assemblies. The completed arc chute assemblies are then moved to operator 4, where they are assembled with arriving bi-metals, handle arms, cross bars to form the base assembly. The base assemblies are then moved to calibration station, where operator 5 checks the calibration of the each circuit breaker. After the circuit-breakers are calibrated, they are transferred to operator 6 for final inspection. The units fail the final inspection are discarded, and the units pass the final inspection are sent to operator 7 for packaging. Once operator 7 completes the packaging, the circuit-breakers leave the assembly line for shipment.

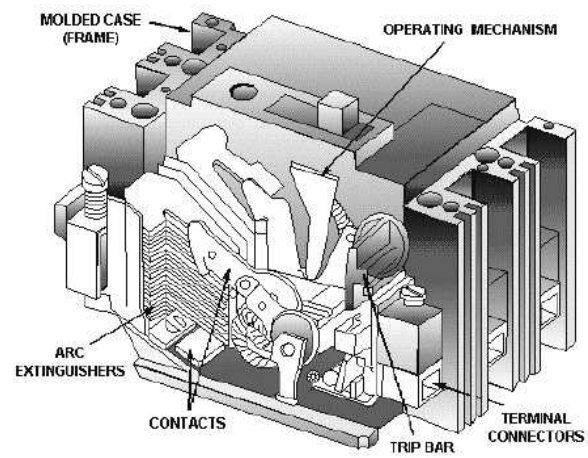

Figure 1: Circuit Breaker Components (TPub)

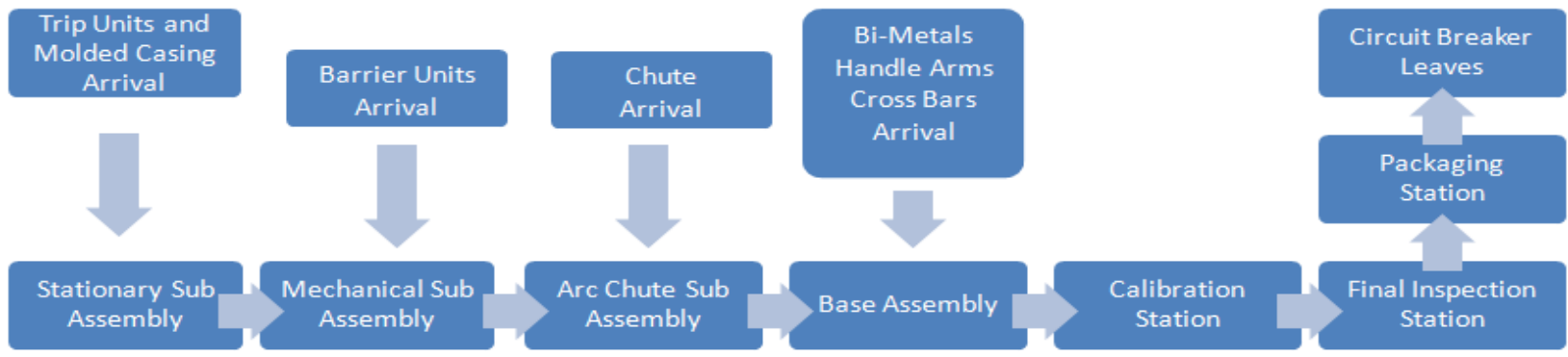

Figure 2: A Circuit - Breaker Assembly Line Layout

As operators work on a given task, they learn and gain experience, and as they gain experience they get better at their tasks which results in fewer scrapped parts indicating higher reliability and attention levels of the experienced operators. For cost estimating purposes NASA (2007) provided average learning curves for various industries and tasks; for repetitive electrical operations the average is around $75-85 \%$, and for operations that require $75 \%$ hand assembly and $25 \%$ machining, the learning level is around $80 \%$.

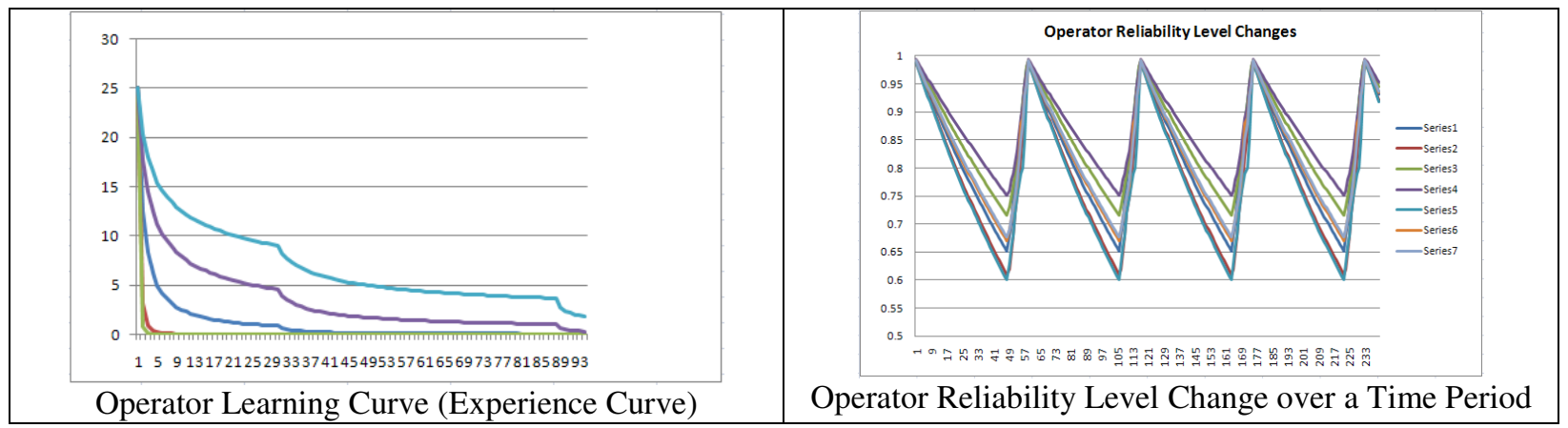

Figure 3: Operator Learning (Experience) Curves and Reliability Level Change over a Time Period 


\section{Altuger and Chassapis}

The learning and experience curve for each operator can be modeled using the Henderson's Law provided in Equation 1, where $C_{1}$ denotes the cost of the first unit, $C_{\eta}$ denotes the cost of the $\eta^{\text {th }}$ unit of production, $\eta$ is the cumulative volume of production and $\alpha$ denotes the elasticity of cost. The individual operators' learning curves can be modeled as show in right side of Figure 3 which can be interpreted as different reliability levels and attention spans as shown in the left side of Figure 3.

$$
C_{\eta}=C_{1} * \eta^{-\alpha}
$$

\subsection{Problem Definition}

Scheduling carries critical importance in production processes, since utilization and performance of the line directly gets affected by the changes in the scheduling of the machines and operators. Therefore it is important to select the most suitable scheduling for the production line at hand. In this study, the different operator break scheduling techniques will be developed:

Global Break Schedule (GBS): The GBS method assumes that the operators in a production line go on a break for a certain period of time and when operators complete their break is completed, they go back to work. The time the operators need to go to break can be set when the first operator reaches a certain minimum allowable attention level.

Reliability - Based Break Schedule (RBS): The RBS method assumes that all operators start their shift with a $100 \%$ attention level, and as they work their reliability levels decrease due to their attention spans. Since every operator has a different attention span, the rates of decrease in their reliabilities are different. The minimum acceptable reliability level that an operator can work is set depending on the needs of the process at hand. Throughout this study, it is assumed that if an operator's attention level drop under a certain limit, there is a high chance that operators produce faulty parts, highlighting the direct correlation between operator attention span and reliability levels. When calculating the operator reliabilities, $\mathrm{R}(\mathrm{t}) \mathrm{de}-$ notes the reliability of an operator at a given t time, and $\lambda$ is the distribution parameter and can be obtained from operator's overall work performance provided in Equations 2a and 2b. Mean Time to Break (MTTB) denotes the mean time until the operator needs a break. This value is based on operators' historical behaviors throughout a shift, their attention and skill levels. The overall reliability of the line operators can be calculated using Equation 2c.

$$
R(t)=e^{-\lambda t} \quad \text { (a) } \quad \text { MTTB }=\frac{1}{\lambda} \quad \text { (b) } \quad R_{\text {line }}=R_{1} * R_{2} * R_{3} * R_{4} * R_{5} * R_{6} * R_{7} \text { (c) }
$$

Value - Based Break Schedule (VBS): The VBS is based on the value method, where each operator carries a value depending on where they are located in the assembly line. A part's value increases as it travels from start to finish in an assembly line. Therefore operators located towards the end of the assembly line work on higher valued parts which will have higher penalties if lost, therefore those operators located towards the end of the line will have higher values than the operators located in the beginning of the line, from the break point of view. For the circuit breaker assembly line under consideration, the value of the operators can be ranked as $7 \rightarrow 6 \rightarrow 5 \rightarrow 4 \rightarrow 3 \rightarrow 2 \rightarrow 1$ from highest to lowest.

\subsection{Arena - Based Simulation Model for the Manual Circuit Breaker Assembly Line}

In order to properly model the manual assembly line behavior, Arena's packaging template has been used. The machine module located in the packaging template is used to model operator attention span and reliability levels as well as operator speed and failure rates. Following the circuit breaker assembly line layout provided in Figure 2, an Arena layout model has been built, as shown in Figure 4. All stations including the part arrivals are built using the station module in Arena. For the part arrival modules (trip unit arrival, molded case arrival, barrier unit arrival, and chute arrival), it is assumed that parts arrive at a certain speed, and the reliability of the part arrivals are $100 \%$ at all times, with no pre - set failure rate or condition. All station modules are connected with the machine links, which have no effect on the simula- 


\section{Altuger and Chassapis}

tion outcome. Throughout this case study, seven operators are considered in controlling the station sub assembly, mechanical sub assembly, arc chute sub assembly, base assembly, calibration station, final inspection station, and packaging station. For all seven operators; operator attention spans (reliabilities), operator skills, operator hourly rates and operator loss rates are considered. For this case study, it is assumed that the operators have all the parts ready and available to them all the time.

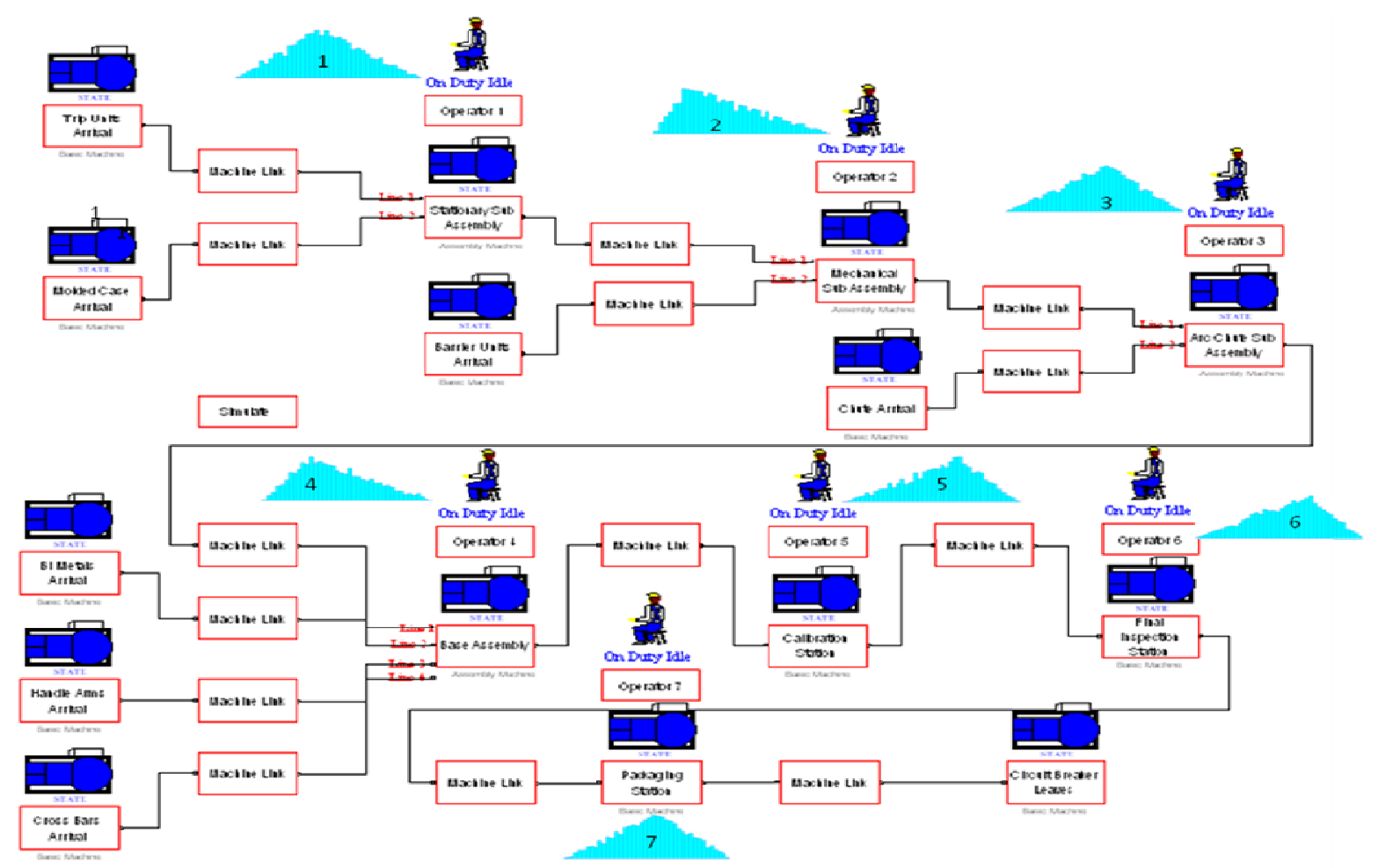

Figure 4: Arena Model of the Circuit - Breaker Assembly Line

Station modules enable the users to define the station, and operator parameters such as cost, speed, failure type, rate, and schedule. For all the part arrivals and leaves the machine type is defined as "machine starts a line and "machine ends a line", respectively. For all other stations, machine module is set as a "basic machine" where the machine's processing rate can be defined individually for every station. For all the processing stations, where operators manually perform the assigned tasks, the machine module will be set in such a way to reflect the operator's characteristics. Figure 5 shows the machine module set - up details for the Base Assembly Station.

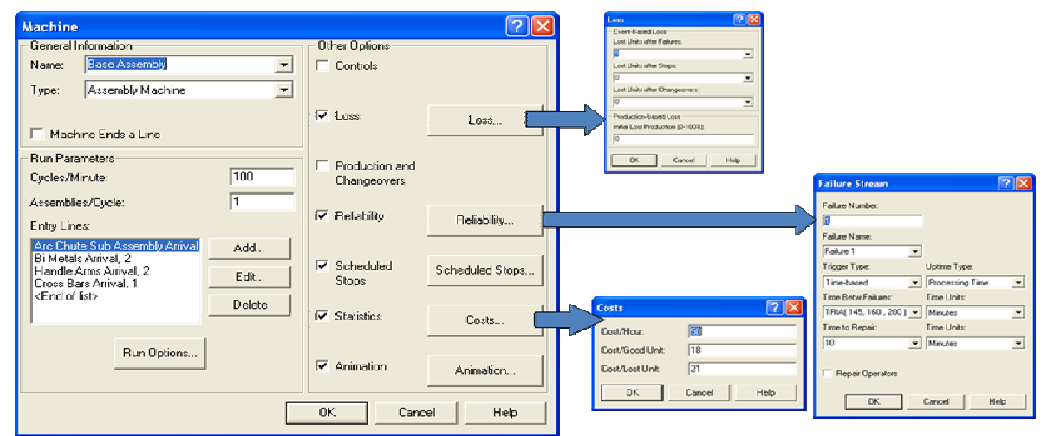

Figure 5: Base Assembly Station Development 


\section{Altuger and Chassapis}

\subsubsection{Input Data Generation}

Appropriately modeling the manual assembly line using Arena's packaging template requires properly collecting and introducing the input data to the model. As the input data for the station modules, a timebased trigger system will be used. Table 1 provides the operator attention span, loss units per operator and reliability schedules when GBS, RBS and VBS will be performed.

Table 1: System Parameters for GBS, RBS and VBS for the Arena Model

\begin{tabular}{|c|c|c|c|c|c|c|c|c|}
\hline \multicolumn{2}{|c|}{ INPUT PARAMETERS } & $\begin{array}{c}\text { Operator } \\
\text { One }\end{array}$ & $\begin{array}{c}\text { Operator } \\
\text { Two }\end{array}$ & $\begin{array}{c}\text { Operator } \\
\text { Three }\end{array}$ & $\begin{array}{c}\text { Operator } \\
\text { Four }\end{array}$ & $\begin{array}{c}\text { Operator } \\
\text { Five }\end{array}$ & $\begin{array}{c}\text { Operator } \\
\text { Six }\end{array}$ & $\begin{array}{c}\text { Operator } \\
\text { Seven }\end{array}$ \\
\hline Run Parameters & Units/Minute & 100 & 100 & 100 & 100 & 100 & 100 & 100 \\
\hline \multirow{11}{*}{$\begin{array}{c}\text { Reliability } \\
\text { and Break } \\
\text { Parameters }\end{array}$} & Trigger Type & \multicolumn{7}{|c|}{ Time - Based } \\
\hline & $\begin{array}{c}\text { Operator } \\
\text { Attention Span } \\
\text { (minutes) }\end{array}$ & 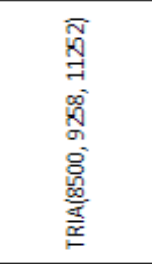 & 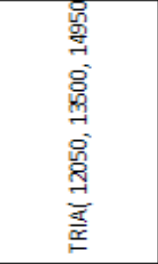 & 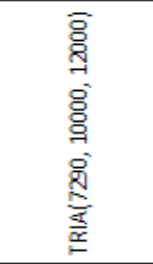 & 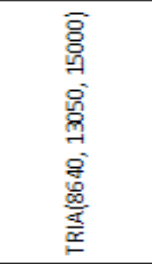 & 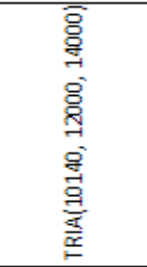 & 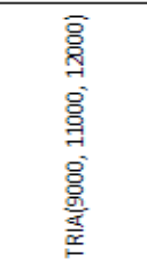 & 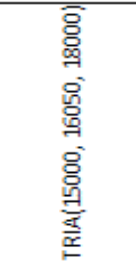 \\
\hline & \multirow{3}{*}{ GBS } & $46 \mathrm{~m}(60 \%)$ & $46 \mathrm{~m}(60 \%)$ & $46 \mathrm{~m}(60 \%)$ & $46 \mathrm{~m}(60 \%)$ & $46 \mathrm{~m}(60 \%)$ & $46 \mathrm{~m}(60 \%)$ & $46 \mathrm{~m}(60 \%)$ \\
\hline & & $56 \mathrm{~m}(55 \%)$ & $56 \mathrm{~m}(55 \%)$ & $56 \mathrm{~m}(55 \%)$ & $56 \mathrm{~m}(55 \%)$ & $56 \mathrm{~m}(55 \%)$ & $56 \mathrm{~m}(55 \%)$ & $56 \mathrm{~m}(55 \%)$ \\
\hline & & $65 \mathrm{~m}(50 \%)$ & $65 \mathrm{~m}(50 \%)$ & $65 \mathrm{~m}(50 \%)$ & $65 \mathrm{~m}(50 \%)$ & $65 \mathrm{~m}(50 \%)$ & $65 \mathrm{~m}(50 \%)$ & $65 \mathrm{~m}(50 \%)$ \\
\hline & \multirow{3}{*}{ RBS } & $57 \mathrm{~m}(60 \%)$ & $49 \mathrm{~m}(60 \%)$ & $73 \mathrm{~m}(60 \%)$ & $85 \mathrm{~m}(60 \%)$ & $106 \mathrm{~m}(60 \%)$ & $61 \mathrm{~m}(60 \%)$ & $62 \mathrm{~m}(60 \%)$ \\
\hline & & $66 \mathrm{~m}(55 \%)$ & $57 \mathrm{~m}(55 \%)$ & $85 \mathrm{~m}(55 \%)$ & $100 \mathrm{~m}(55 \%)$ & $122 \mathrm{~m}(55 \%)$ & $71 \mathrm{~m}(55 \%)$ & $73 \mathrm{~m}(55 \%)$ \\
\hline & & $77 \mathrm{~m}(50 \%)$ & $67 \mathrm{~m}(50 \%)$ & $99 \mathrm{~m}(50 \%)$ & $116 \mathrm{~m}(50 \%)$ & $140 \mathrm{~m}(50 \%)$ & $83 \mathrm{~m}(50 \%)$ & $85 \mathrm{~m}(50 \%)$ \\
\hline & \multirow{3}{*}{ VBS } & $122 \mathrm{~m}(60 \%)$ & $112 \mathrm{~m}(60 \%)$ & $102 \mathrm{~m}(60 \%)$ & $92 \mathrm{~m}(60 \%)$ & $82 \mathrm{~m}(60 \%)$ & $72 \mathrm{~m}(60 \%)$ & $62 \mathrm{~m}(60 \%)$ \\
\hline & & $133 \mathrm{~m}(55 \%)$ & $123 \mathrm{~m}(55 \%)$ & $133 \mathrm{~m}(55 \%)$ & $103 \mathrm{~m}(55 \%)$ & $93 \mathrm{~m}(55 \%)$ & $83 \mathrm{~m}(55 \%)$ & $73 \mathrm{~m}(55 \%)$ \\
\hline & & $145 \mathrm{~m}(50 \%)$ & $135 \mathrm{~m}(50 \%)$ & $125 \mathrm{~m}(50 \%)$ & $115 \mathrm{~m}(50 \%)$ & $105 \mathrm{~m}(50 \%)$ & $95 \mathrm{~m}(50 \%)$ & $85 \mathrm{~m}(50 \%)$ \\
\hline $\begin{array}{l}\text { Loss } \\
\text { Parameters }\end{array}$ & Loss Units & 1 & 1 & 1 & 1 & 1 & 1 & 1 \\
\hline
\end{tabular}

To collect meaningful data and to model the assembly line behavior correctly, the simulation parameters are set as realistically as possible. The simulations considered 8 hours/shift, 1 shift/day, 5 days/week, and 4 weeks/month, and the monthly behavior is modeled with 20 replications.

\subsubsection{Output Data Collection}

Once the simulation model is ready and simulation parameters are set, the challenge remains "which outputs one needs to observe?". For the manual circuit breaker assembly line case study, it is determined that utilization of the line, average output factor per replication (day), operator blocked and starved times as well as overall cost of good and lost products are directly affected with the break schedule changes. Table 2 provides the measures that will be examined as simulation output for the case study.

Table 2: Evaluation Measures for the Three Scenarios $(60 \%, 55 \%, 50 \%)$ under consideration

\begin{tabular}{|c|c|}
\hline Average Output Factor (AOF) & The ratio of the Average Output Rate greater than zero \\
\hline Utilization (U) & Utilization $=\frac{(\text { Total_Time_Output_Rate_Greater_Than_0 })}{(\text { Simulation_Run_Length }- \text { Total_Time_Stopped })}$ \\
\hline Total Time Blocked (TTB) & The total time the machine was in the Blocked state \\
\hline Total Time Starved (TTS) & The total time the machine was in the Starved state \\
\hline Cost of Good Product (CGP) & $C G P=($ Total_Good_Units_Produced $) *($ Cost / Good_Unit $)$ \\
\hline Cost of Lost Product (CLP) & $C L P=($ Total_Units__Lost $) *($ Cost / Lost_Unit $)$ \\
\hline
\end{tabular}

Once the evaluation measures for the production line at hand are determined, the output values for all three scenarios for all three minimum allowable reliability levels are collected to be used in the multi cri- 


\section{Altuger and Chassapis}

teria decision making process. Table 3 provides an overall summary of the simulation outcomes of the nine scenarios considered for the circuit breaker assembly line case study.

Table 3: Evaluation Measures for the Three Scenarios $(60 \%, 55 \%, 50 \%)$ under consideration

\begin{tabular}{|c|c|c|c|c|c|c|c|c|c|c|c|c|c|c|c|c|c|c|c|}
\hline ATTRIBUTE & $\begin{array}{l}\text { GMO - } \\
60 \%\end{array}$ & $\begin{array}{l}\text { GMO- } \\
55 \%\end{array}$ & $\begin{array}{l}\text { GMO - } \\
50 \%\end{array}$ & $\begin{array}{l}\text { RMO - } \\
60 \%\end{array}$ & $\begin{array}{l}\text { RMO - } \\
55 \%\end{array}$ & $\begin{array}{l}\text { RMO - } \\
50 \%\end{array}$ & $\begin{array}{l}\text { VMO - } \\
60 \%\end{array}$ & $\begin{array}{l}\text { VMO- } \\
55 \%\end{array}$ & $\begin{array}{l}\text { VMO- } \\
50 \%\end{array}$ & ATTRIBUTE & $\begin{array}{l}\text { GMO - } \\
60 \%\end{array}$ & $\begin{array}{l}\text { GMO- } \\
55 \%\end{array}$ & $\begin{array}{l}\text { GMO- } \\
50 \%\end{array}$ & $\begin{array}{l}\text { RMO- } \\
60 \%\end{array}$ & $\begin{array}{l}\text { RMO - } \\
55 \%\end{array}$ & $\begin{array}{l}\text { RMO - } \\
50 \%\end{array}$ & $\begin{array}{l}\text { VMO - } \\
60 \%\end{array}$ & $\begin{array}{l}\text { VMO - } \\
55 \%\end{array}$ & $\begin{array}{c}\text { VMO- } \\
50 \%\end{array}$ \\
\hline Average Output Factor & & & & & & & & & & Total Good Units & & & & & & & & & \\
\hline Stationary Sub Assembly & 0.53 & 0.52 & 0.50 & 0.50 & 0.50 & 0.50 & 0.50 & 0.50 & 0.50 & Stationary Sub Assembly & 255.00 & 193.00 & 970.00 & 2216.00 & 2886.00 & 3267.00 & 3634.00 & 3613.00 & 4380.00 \\
\hline Mechar & 0.59 & 0.57 & 51 & 0.62 & 0.65 & 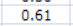 & 57 & 0.67 & 0.68 & echanical Sub & 255.00 & 33.00 & 970.00 & 2216.00 & 2886.00 & 3267.00 & 3634.00 & 3613.00 & 4380.00 \\
\hline Arc Chute $\$$ & 0.66 & 0.63 & 0.51 & 0. & 0.74 & 0 & 78 & 0.78 & 0.81 & c Chute & 255.00 & 93.00 & 970.00 & 2216.00 & 2886.00 & 67.00 & 3634.00 & 13.00 & 80.00 \\
\hline ase Assen & 0.62 & 0 & 0.50 & 0.5 & 0.50 & 0.5 & 0.50 & 0.50 & 0.50 & Base & 25 & 00 & 970.00 & 221 & 2886.00 & 7.00 & 3634.00 & .00 & 4380.00 \\
\hline Calibration Station & 0.70 & 0. & 0.50 & 0.50 & 50 & 0.50 & 50 & 0.50 & 50 & Calibration Station & 255.00 & 193.00 & 970.00 & 2216.00 & 2886.00 & 3267.00 & 3634.00 & 3613.00 & 4380.00 \\
\hline Final Inspection Station & 0.75 & 0.73 & 0.51 & 0.50 & 0.50 & 50 & 0.50 & 0.5 & 50 & Final Inspe & 255.00 & 193.00 & 970.00 & 2216.00 & 2886.00 & 3267.00 & 3634.00 & 613.00 & 4380.00 \\
\hline $\begin{array}{l}\text { Packaging Station } \\
\text { Cast of Good Product }\end{array}$ & 0.75 & 0.78 & 0.51 & 0.50 & 0.50 & 0.50 & 0.50 & 0.50 & 0.50 & Packaging Station & 255.00 & 193.00 & 970.00 & 2216.00 & 2886.00 & 3267.00 & 3634.00 & 3613.00 & 4380.00 \\
\hline $\begin{array}{l}\text { Cost of Good Product } \\
\text { Stationary Sub Assembly }\end{array}$ & 1021.0 & 775.5 & 3884.5 & 8872.2 & 11554.6 & 13079.1 & 14547.5 & 15658.0 & 17534.7 & $\begin{array}{l}\text { Cost of Lost Product } \\
\text { Stationary Sub Assembly }\end{array}$ & & & & & & & & & \\
\hline Mechanical Sub Assembly & 1863.0 & 1414.9 & 7087.6 & 16189.6 & 21084.0 & 23865.5 & 26545.4 & 28590.5 & 31996.5 & Mechanical s & & & & & & 3. & & 4.15 & 5.33 \\
\hline Arc Chute Sub Assembly & 2296.4 & 1744.0 & 8737.0 & 19957.5 & 25991.1 & 29420.3 & 32724.0 & 35245.4 & 39444.1 & Arc Chute & 0.2 & 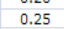 & 1.2. & 2.0 & 2.7 & 3.00 & 3.00 & 3.25 & 3.25 \\
\hline Base A & 4592.7 & 2487.5 & 17472.2 & 39912.3 & 51977.7 & 58833.5 & 65441.7 & 90482.6 & 78883.2 & & & & & 4.2 & & 7. & & & 88 \\
\hline Calibration Station & 5612.8 & 4262.5 & 21351.0 & 48773.5 & 63516.8 & 71895.5 & 79971.1 & 86129.5 & 96393.6 & Calibration Station & & 0. & 3. & 7.88 & 11.81 & 11.81 & 13.50 & 15.75 & 19.69 \\
\hline Final Inspection Station & 5867.3 & 4455.7 & 22318.1 & 50983.5 & 66394.1 & 75154.3 & 83594.7 & 90030.5 & 100760 & Final Inspecti & 0.5 & 0.5 & 3.5 & 7.0. & 9.99 & 9.40 & 11.75 & 14.10 & 15.86 \\
\hline Packaging Station & 6121.8 & 4649.4 & 23287.8 & 53193.6 & 69271.2 & 78410.4 & 87217.2 & 93930.0 & 105126 & Station & 0.61 & 0.00 & 0.61 & 6.74 & 9.80 & 11.03 & 12.25 & 14.09 & 14.70 \\
\hline $\begin{array}{l}\text { Total Units } \\
\text { cationary Sub A }\end{array}$ & 1.00 & 1.00 & 1.00 & 1.00 & 00 & 1.6 & 00 & 1.0 & $1.6 \mathrm{C}$ & ationary s & 2.47 & & & & 27 & & 32.57 & 34.96 & 38.85 \\
\hline Mechanical S. & 1.00 & 1.00 & 1.00 & 1.00 & 1.00 & 1.00 & 1.00 & 1.00 & 1.00 & Mechanical & 2.3 & $1.8 \mathrm{Y}$ & & 17.54 & 21.73 & 25.46 & 24.77 & 26.56 & 28.91 \\
\hline Arc Chute Sub Assembly & 1.00 & 1.00 & 1.00 & 1.00 & 1.00 & 1. & 1.00 & 1. & 1.00 & Arc Chute & & 1.7 & 8.8 & 15.21 & 18.48 & 22.36 & 21.68 & 23.18 & 24.75 \\
\hline & 0.00 & & & & & & & & & & & & & & & & & & \\
\hline Calibr & 1.0 & & & & 1. & & & & & & & & & & & & & 35.92 & \\
\hline Final Inspection Station & 1.00 & & 1.00 & & 1.00 & & 1.00 & 1. & 1.0 & Final In & 2. & 1.7 & 9. & 21.33 & 27.23 & 30.26 & 34.27 & 36.21 & 40.09 \\
\hline Packaging Station & 1.00 & 0.00 & 1.00 & 1.00 & 1.00 & 1.00 & 1.00 & 1.00 & 1.00 & Packaging Station & 2.47 & 1.78 & 9.21 & 21.27 & 27.16 & 30.22 & 34.99 & 36.85 & 40.53 \\
\hline Total Ti & & & & & & & & & & & & & & & & & & & \\
\hline & 3.2 & & & & & & & & & & & & & & & & & 0 & 0.00 \\
\hline & 2. & & & & & & & & & & & 0. & & & & & & 0. & 0.36 \\
\hline Arc Chute & 1.87 & & 2. & & 1.8 & & 2. & 2. & 2. & echl & & 1. & 1 & 1. & 1. & 0.9 & 0.74 & 0 & 0.70 \\
\hline & 1.19 & 1.5 & 1.5 & 1. & 1.2 & 1. & 1.2 & 1. & 1. & $\mathrm{Ba}$ & 2. & 1. & 1. & 1 & 1. & 1.31 & 1. & 1. & 0.98 \\
\hline $\mathrm{Ca}-\mathrm{Cl}_{2}$ & 0.52 & 0.9 & 0.9 & 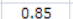 & 0.72 & 0.73 & 0.8 & 0. & 0. & Calit & 2. & 2.3 & 2. & 1. & 1. & 1.5 & 1. & 1. & 1.29 \\
\hline Final Inspection S & 0.00 & $0.3-3 x-3 x$ & 0.4 & 0. & 0.3 & 0. & $0.4 .250-10$ & 0. & 0. & Final Ins & 3. & 2. & 2. & 2 & 2 & 2. & 2. & 1. & 2.55 \\
\hline Packaging Station & 0.00 & 0.00 & 0.00 & 0.00 & 0.00 & 0.00 & 0.00 & 0.00 & 0.00 & Packaging Station & 3.23 & 3.33 & 3.13 & 2.65 & 2.49 & 2.41 & 2.15 & 2.12 & 1.65 \\
\hline
\end{tabular}

\section{DECISION MAKING VIA HIERARCHICAL AGGREGATION}

\subsection{Hierarchical Multi Criteria Decision Making}

When deciding the most appropriate break schedule, one needs to define which evaluation measure is more important over the others and how to assign numerical values for the rankings. Altuger and Chassapis (2009a) proposed the Hierarchical Weight Assessment (HWA) approach that assigns weight values based on the hierarchical rankings and the numerical values of the evaluation measures. In this study, the HWA method will be implemented when performing weight calculations for the evaluation measures. Table 4 provides the HWA calculation steps and template for a multi criteria decision making problem.

Table 4: HWA Template Formation (Altuger and Chassapis 2009a)

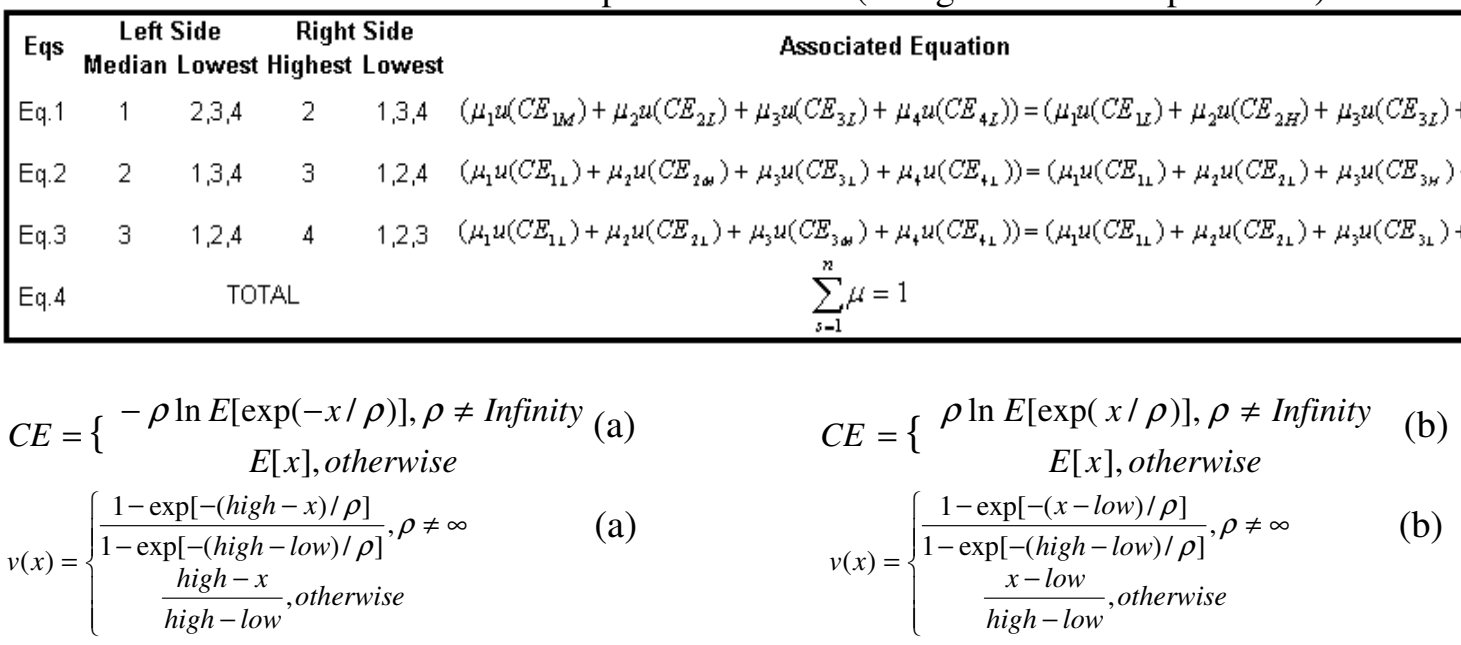

The calculation of the deterministic and probabilistic Certainty Equivalent (CE) values depend on whether higher or lower values are preferred (Equations 3a-b, 4a-b respectively), where x denoting the current value and $\rho$ being the exponential constant. 


\section{Altuger and Chassapis}

\subsection{Calculation of Weight Values}

When deciding if higher or lower values are preferred, each evaluation measure is examined separately with respect to the assembly process. When the output values of the circuit breaker assembly line are considered, higher values of AOF), Utilization (U), and Cost of Good Product (CGP) are preferred, whereas lower values of Total Time Blocked (TTB), Total Time Starved (TTS) and Cost of Lost Product (CLP) are chosen. Weight values of the evaluation measures provided in Table 2 are calculated using the HWA template. In order to properly determine the most appropriate break schedule for the operators, 9 different scenarios have been considered for 8 different hierarchical rankings. The considered scenarios are: GBS 60\%, GBS 55\%, GBS 50\%, RBS 60\%, RBS 55\%, RBS 50\%, VBS 60\%, VBS 55\%, AND VBS $50 \%$. The calculated weight values for all 9 scenarios for different rankings are shown in Tables 5 - 12.

\section{HIERARCHICAL PREFERENCE AGGREGATION DECISION PROCESS OUTCOME}

\subsection{Decision - Making Outputs}

Once the scenarios and the different hierarchical rankings are set, the decision-making process using the HWA was performed for each hierarchical ranking. The weight outcomes for sample scenarios are listed in detail in Tables 5,6 and 7. When examined closely, it can be seen that in some cases the outcome weight values' rankings may not fully follow the initial rankings, such as in Table 7. This may be due to the weight value distribution as well as having weight outputs very close to each other.

Table 5: Hierarchical Ranking from higher to lower: U, AOF, TTB, TTS, CGP, CLP

\begin{tabular}{|c|c|c|c|c|c|c|c|c|c|c|c|c|c|c|c|c|c|c|c|}
\hline Evaluation $\mathrm{M}$ & Weight & $\begin{array}{c}\text { GBS - } \\
60 \%\end{array}$ & $\begin{array}{l}\text { Weighted } \\
\text { Grade }\end{array}$ & $\begin{array}{c}\text { GBS - } \\
55 \%\end{array}$ & $\begin{array}{l}\text { Weighted } \\
\text { Grade }\end{array}$ & $\begin{array}{l}\text { GBS - } \\
50 \%\end{array}$ & $\begin{array}{c}\text { Weighted } \\
\text { Grade }\end{array}$ & $\begin{array}{l}\text { RBS - } \\
60 \%\end{array}$ & $\begin{array}{c}\text { Weighted } \\
\text { Grade }\end{array}$ & $\begin{array}{l}\text { RBS - } \\
55 \%\end{array}$ & $\begin{array}{l}\text { Weighted } \\
\text { Grade }\end{array}$ & $\begin{array}{l}\text { RBS - } \\
50 \%\end{array}$ & $\begin{array}{c}\text { Weighted } \\
\text { Grade }\end{array}$ & $\begin{array}{c}\text { VBS - } \\
60 \%\end{array}$ & $\begin{array}{c}\text { Weighted } \\
\text { Grade }\end{array}$ & $\begin{array}{l}\text { VBS - } \\
55 \%\end{array}$ & $\begin{array}{c}\text { Weighted } \\
\text { Grade }\end{array}$ & $\begin{array}{l}\text { VBS - } \\
50 \%\end{array}$ & $\begin{array}{c}\text { Weighted } \\
\text { Grade }\end{array}$ \\
\hline Average Output Factor & 0.4580 & 1.0000 & 0.4580 & 0.6609 & 0.3027 & 0.6248 & 0.2861 & 0.0275 & 0.0126 & 0.0140 & 0.0064 & 0.0210 & 0.0096 & 0.0088 & 0.0040 & 0.0080 & 0.0037 & 0.0000 & 0.0000 \\
\hline Total Time Blocked & 0.0210 & 0.0000 & 0.0000 & 0.3746 & 0.0079 & 0.4613 & 0.0097 & 0.5764 & 0.0121 & 0.5724 & 0.0120 & 0.6232 & 0.0131 & 0.8876 & 0.0186 & 0.9335 & 0.0196 & 1.0000 & 0.0210 \\
\hline Total Time Starved & 0.0080 & 1.0000 & 0.0080 & 0.6678 & 0.0053 & 0.5630 & 0.0045 & 0.5933 & 0.0047 & 0.6563 & 0.0053 & 0.5995 & 0.0048 & 0.0923 & 0.0007 & 0.4759 & 0.0038 & 0.0000 & 0.0000 \\
\hline Utilization & 0.5090 & 0.8834 & 0.4497 & 0.0000 & 0.0000 & 0.9675 & 0.4925 & 0.9151 & 0.4658 & 0.9526 & 0.4849 & 0.9304 & 0.4736 & 0.9015 & 0.4588 & 0.9527 & 0.4849 & 1.0000 & 0.5090 \\
\hline Cost of Lost Product & 0.0020 & 1.0000 & 0.0020 & 0.0000 & 0.0000 & 0.3827 & 0.0008 & 0.5486 & 0.0011 & 0.5495 & 0.0011 & 0.6077 & 0.0012 & 0.5969 & 0.0012 & 0.5524 & 0.0011 & 0.3996 & 0.0008 \\
\hline Cost of Good Product & 0.0020 & 1.0000 & 0.0020 & 0.0000 & 0.0000 & 0.2477 & 0.0005 & 0.2480 & 0.0005 & 0.2481 & 0.0005 & 0.2481 & 0.0005 & 0.2481 & 0.0005 & 0.4933 & 0.0010 & 0.2482 & 0.0005 \\
\hline Final Grade & & & 0.9197 & & 0.3159 & & 0.7941 & & 0.4968 & & 0.5101 & & 0.5028 & & 0.4839 & & 0.5141 & & 0.5313 \\
\hline
\end{tabular}

Table 6: Hierarchical Ranking from higher to lower: TTB, U, TTS, CGP, CLP, AOF

\begin{tabular}{|c|c|c|c|c|c|c|c|c|c|c|c|c|c|c|c|c|c|c|c|}
\hline Evaluat & Weight & $\begin{array}{c}\text { GBS - } \\
60 \% \\
\end{array}$ & $\begin{array}{c}\text { Weighted } \\
\text { Grade }\end{array}$ & $\begin{array}{c}\text { GBS - } \\
55 \%\end{array}$ & $\begin{array}{l}\text { Weighted } \\
\text { Grade }\end{array}$ & $\begin{array}{c}\text { GBS - } \\
50 \%\end{array}$ & $\begin{array}{c}\text { Weighted } \\
\text { Grade }\end{array}$ & $\begin{array}{c}\text { RBS - } \\
60 \% \\
\end{array}$ & $\begin{array}{c}\text { Weighted } \\
\text { Grade }\end{array}$ & $\begin{array}{c}\text { RBS - } \\
55 \%\end{array}$ & $\begin{array}{c}\text { Weighted } \\
\text { Grade }\end{array}$ & $\begin{array}{c}\text { RBS - } \\
50 \%\end{array}$ & $\begin{array}{c}\text { Weighted } \\
\text { Grade }\end{array}$ & $\begin{array}{l}\text { VBS - } \\
60 \% \\
\end{array}$ & $\begin{array}{c}\text { Weighted } \\
\text { Grade }\end{array}$ & $\begin{array}{l}\text { VBS - } \\
55 \%\end{array}$ & $\begin{array}{l}\text { Weighted } \\
\text { Grade }\end{array}$ & $\begin{array}{l}\text { VBS - } \\
50 \%\end{array}$ & $\begin{array}{c}\text { Weighted } \\
\text { Grade } \\
\end{array}$ \\
\hline t Factor & 0.0100 & 1.0000 & 0.0100 & 0.6609 & 0.0066 & 0.6248 & 0.0062 & 0.0275 & 0.0003 & 0.0140 & 0.0001 & 0.0210 & 0.0002 & 0.0088 & 0.0001 & 0.0080 & 0.0001 & 0.0000 & 0.0000 \\
\hline Total Time Blocked & 0.5600 & 0.0000 & 0.0000 & 0.3746 & 0.2098 & 0.4613 & 0.2583 & 0.5764 & 0.3228 & 0.5724 & 0.3206 & 0.6232 & 0.3490 & 0.8876 & 0.4971 & 0.9335 & 0.5228 & 1.0000 & 0.5600 \\
\hline Total Time Starved & 0.2100 & 1.0000 & 0.2100 & 0.6678 & 0.1402 & 0.5630 & 0.1182 & 0.5933 & 0.1246 & 0.6563 & 0.1378 & 0.5995 & 0.1259 & 0.0923 & 0.0194 & 0.4759 & 0.0999 & 0.0000 & 0.0000 \\
\hline Utilization & 0.1100 & 0.8834 & 0.0972 & 0.0000 & 0.0000 & 0.9675 & 0.1064 & 0.9151 & 0.1007 & 0.9526 & 0.1048 & 0.9304 & 0.1023 & 0.9015 & 0.0992 & 0.9527 & 0.1048 & 1.0000 & 0.1100 \\
\hline Cost of Lost Product & 0.0100 & 1.0000 & 0.0100 & 0.0000 & 0.0000 & 0.3827 & 0.0038 & 0.5486 & 0.0055 & 0.5495 & 0.0055 & 0.6077 & 0.0061 & 0.5969 & 0.0060 & 0.5524 & 0.0055 & 0.3996 & 0.0040 \\
\hline Cost of Good Product & 0.1000 & 1.0000 & 0.1000 & 0.0000 & 0.0000 & 0.2477 & 0.0248 & 0.2480 & 0.0248 & 0.2481 & 0.0248 & 0.2481 & 0.0248 & 0.2481 & 0.0248 & 0.4933 & 0.0493 & 0.2482 & 0.0248 \\
\hline Final Grade & & & 0.4272 & & 0.3566 & & 0.5178 & & 0.5786 & & 0.5936 & & 0.6083 & & 0.6465 & & 0.7824 & & 0.6988 \\
\hline
\end{tabular}

Table 7: Hierarchical Ranking from higher to lower: CLP, CGP, U, TTS, TTB, AOF

\begin{tabular}{|c|c|c|c|c|c|c|c|c|c|c|c|c|c|c|c|c|c|c|c|}
\hline Eva & Weight & $\begin{array}{c}\text { GBS - } \\
60 \% \\
\end{array}$ & $\begin{array}{c}\text { Weighted } \\
\text { Grade }\end{array}$ & $\begin{array}{c}\text { GBS - } \\
55 \% \\
\end{array}$ & $\begin{array}{c}\text { Weighted } \\
\text { Grade }\end{array}$ & $\begin{array}{c}\text { GBS - } \\
50 \%\end{array}$ & $\begin{array}{c}\text { Weighted } \\
\text { Grade }\end{array}$ & $\begin{array}{l}\text { RBS - } \\
60 \%\end{array}$ & $\begin{array}{c}\text { Weighted } \\
\text { Grade }\end{array}$ & $\begin{array}{c}\text { RBS - } \\
55 \%\end{array}$ & $\begin{array}{c}\text { Weighted } \\
\text { Grade }\end{array}$ & $\begin{array}{l}\text { RBS - } \\
50 \%\end{array}$ & $\begin{array}{c}\text { Weighted } \\
\text { Grade }\end{array}$ & $\begin{array}{l}\text { VBS - } \\
60 \%\end{array}$ & $\begin{array}{c}\text { Weighted } \\
\text { Grade }\end{array}$ & $\begin{array}{l}\text { VBS - } \\
55 \%\end{array}$ & $\begin{array}{c}\text { Weighted } \\
\text { Grade }\end{array}$ & $\begin{array}{l}\text { VBS - } \\
50 \%\end{array}$ & $\begin{array}{c}\text { Weighted } \\
\text { Grade }\end{array}$ \\
\hline 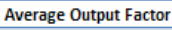 & 0.0650 & 1.0000 & 0.0650 & 0.6609 & 0.0430 & 0.6248 & 0.0406 & 0.0275 & 0.0018 & 0.0140 & 0.0009 & 0.0210 & 0.0014 & 0.0088 & 0.0006 & .0080 & 0.0005 & 0.0000 & 0.0000 \\
\hline Total & 0.0350 & 0000 & 0000 & 0.3746 & 31 & 0.4613 & 0.0161 & 0.5764 & 202 & 0.5724 & 200 & 0.6232 & 0218 & 0.8876 & 0311 & .9335 & 0327 & .0000 & 0.0350 \\
\hline Total & 0.0840 & 0000 & 0840 & .6678 & 0561 & .5630 & 0473 & 0.5933 & 498 & .6563 & 0551 & 0.5995 & 0504 & 0.0923 & 0078 & .4759 & 0400 & .0000 & 0.0000 \\
\hline & 0.0470 & 0.8834 & 2415 & .0000 & 0000 & .9675 & 0455 & 0.9151 & 0430 & 9526 & 0.0448 & 0.9304 & 0.0437 & 0.9015 & .0424 & 0.9527 & 0.0448 & 1.0000 & 0.0470 \\
\hline Cost o & 0.3660 & 1.0000 & 3660 & 0.0000 & 0000 & .3827 & 0.1401 & 0.5486 & 2008 & 0.5495 & .2011 & 0.6077 & .2224 & 0.5969 & 0.2185 & .5524 & 0.2022 & 0.3996 & 0.1463 \\
\hline Cost of Good Produ & 0.4030 & 1.0000 & 0.4030 & 0.0000 & 0.0000 & 0.2477 & 0.0998 & 0.2480 & 1000 & 0.2481 & 0.1000 & 0.2481 & 0.1000 & 0.2481 & 0.1000 & 0.4933 & 0.1988 & 0.2482 & 0.1000 \\
\hline Final Grade & & & 0.9595 & & 0.1122 & & 0.3894 & & 0.4156 & & 0.4220 & & 0.4397 & & 0.4002 & & 0.5189 & & 0.3283 \\
\hline
\end{tabular}

The most appropriate break schedule will be selected based on the aggregated utility values, where the scenario that carries the highest utility value for each ranking provides the most appropriate break schedule for that particular ranking. Selecting the break schedule that will provide the most appropriate break schedule regardless of the changes in the rankings is obtained by looking at the sensitivity analysis results for each scenario for each ranking and the overall scenario outcomes. When examining the output weight values, the VBS for 55\% reliability and GBS for $60 \%$ reliability came out as the possible candi- 


\section{Altuger and Chassapis}

dates for the most appropriate break schedule selection process. Among the 8 different hierarchical rankings, 6 weight outcomes favored the GBS $-60 \%$ and 2 favored VBS - 55\%. The Selection between these two candidates can be performed through output sensitivity analysis.

\subsection{Output Sensitivity Analyses}

Sensitivity analyses are performed for each hierarchical ranking and for each scenario under consideration, with the goal of examining how sensitive the weight values are to the changes in the utility values. The ideal weight distribution should provide very little sensitivity when the utility values change. The sensitivity graphs are examined to determine if the calculated weight values using the HWA method are appropriate for the evaluation measures at hand as well as if they fit the overall scenario. Figures 6, 7 and 8 provide the sensitivity graph of the highest ranked evaluation measure for each of the rankings examined in Tables 5, 6 and 7, respectively. The sensitivity graphs are examined for the line steepness and crossings, and can be concluded that Figure 8 provided better weight assessments for the evaluation measures under consideration than Figures 6 and 7. This can be interpreted as the ranking and the weight values obtained in Table 7 is a better fit for the case at hand than the weight values obtained in Tables 5 and 6, which are shown in Figures 6 and 7, respectively.

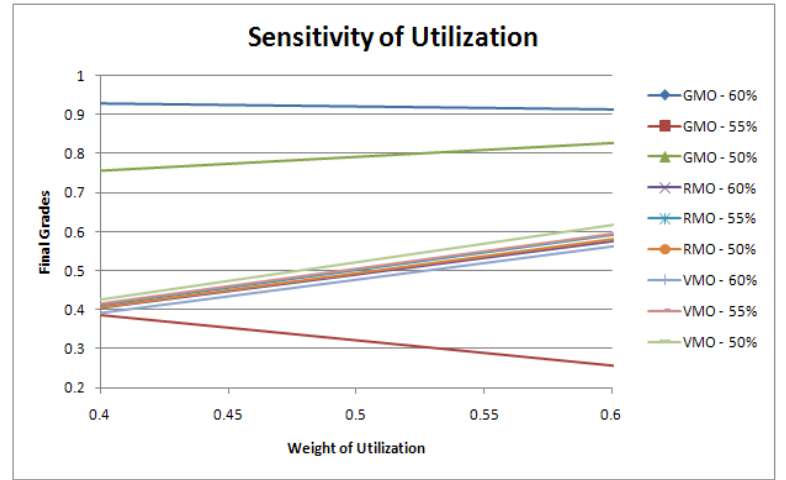

Figure 6: Sensitivity Analysis of U for Table 5's ranking

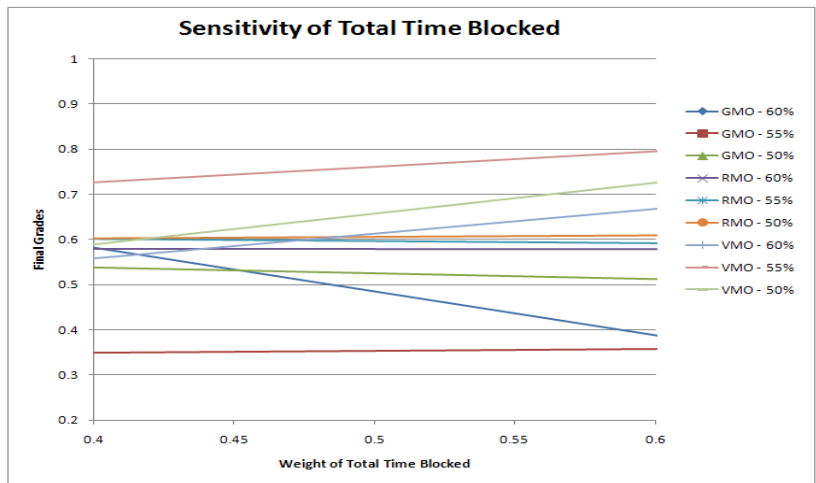

Figure 7: Sensitivity Analysis of TTB for Table 6's ranking

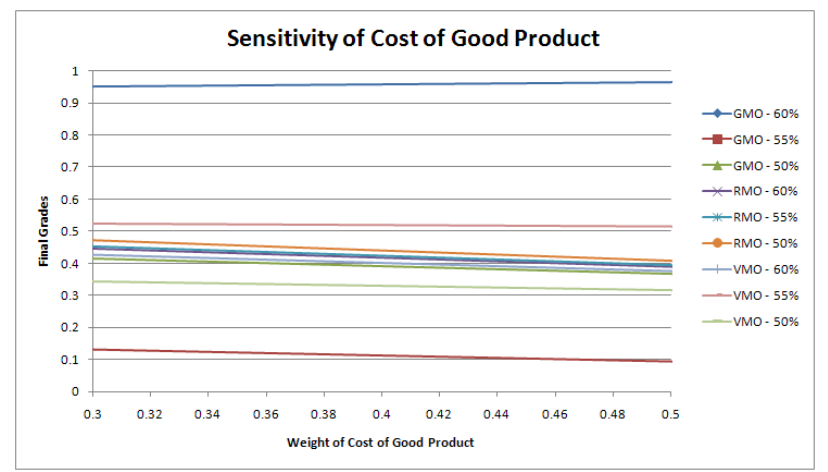

Figure 8: Sensitivity Analysis of CGP for Table 7's ranking

From the sensitivity analysis outcomes, sample set is shown in Figures 6, 7 and 8, and value outcomes, sample set is shown in Tables 5, 6 and 7, the Global Break Schedule with a 60\% minimum reliability level provided the most appropriate scheduling for the manual circuit breaker assembly line under consideration. Even though this method of operator scheduling and staffing may fit the existing assembly line best, it may not be an appropriate fit for other production lines. However, with the implementation of the me- 


\section{Altuger and Chassapis}

thod provided in this study, the most appropriate scheduling technique can be determined for different production lines.

\section{CONCLUSIONS}

This study provides a multi criteria decision making platform that uses a hierarchical weight assessment method to calculate weights based on certainty equivalents and hierarchy of the evaluation measures. The proposed method considers operator behaviors, attention levels, reliabilities and learning (experience) curves. The evaluation measures considered for this case study reflect what is important for this specific process. The proposed decision making method has the flexibility to account for different evaluation measures with different hierarchical rankings. The Arena software's packaging template is also used to model and simulate the behavior of the line, where the workers attention spans are modeled through the reliability levels and failure rates as defined through the station modules.

The method disucussed provides an extensive operator staffing and scheduling layout for the manufacturing and assembly lines, which can be employed and adapted by different manual production lines with different characteristics.

\section{REFERENCES}

Adams, M., P. Componation, H. Czarnecki, and B. J. Schroer. 1999. Simulation as a Tool for Continuous Process Improvement. In Proceedings of the 1999 Winter Simulation Conference, ed P. A. Farrington, H. B. Nembhard, D. T. Sturrock, and G. W. Evans, 766-773. Piscataway, New Jersey: Institute of Electrical and Electronics Engineers, Inc.

Altuger, G., and C. Chassapis. 2009a. An Approach to Facilitate Decision Making In An Integrated Design Environment. In Proceedings of the 2009 International Hellenic Society for Systemic Studies, Xanthi, Greece, June 24-27, 2009

Altuger, G., and C. Chassapis. 2009b. Multi Criteria Preventive Maintenance Scheduling Through Arena Based Simulation Modeling. In Proceedings of the 2009 Winter Simulation Conference, ed. M. D. Rossetti, R. R. Hill, B. Johansson, A. Dunkin and R. G. Ingalls, 2123 - 2134. Piscataway, New Jersey: Institute of Electrical and Electronics Engineers, Inc.

Bevis, F. W., C. Finniea, and D.R. Towill. 1970. Prediction of Operator Performance During Learning of Repetitive Tasks. The International Journal of Production Research, Volume 8, No. 4, pp: 293 - 305

Cassady, C. R., and E. Kutanoglu. 2003. Minimizing Job Tardiness Using Integrated Preventive Maintenance Planning and Production Scheduling, IIE Transactions, 2003, Vol. 35, 503-515

Chong. C. S., A. I. Sivakumar, and R. Gay. 2003. Simulation-Based Scheduling for Dynamic Discrete Manufacturing. In Proceedings of the 2003 Winter Simulation Conference, ed. S. Chick, P. J. Sanchez, D. Ferrin, and D. J. Morrice, 1465-1473. Piscataway, New Jersey: Institute of Electrical and Electronics Engineers, Inc.

Faget, P., U. Eriksson, and F. Herrmann. 2005. Applying Discrete Event Simulation and an Automated Bottleneck Analysis as an Aid to Detect Running Production Constraints. In Proceedings of the 2005 Winter Simulation Conference, ed. M. E. Kuhl, N. M. Steiger, F. B. Armstrong, and J. A. Joines, 1401 - 1407, Piscataway, New Jersey: Institute of Electrical and Electronics Engineers, Inc.

Fixson, S. K. 2004. Assessing Product Architecture Costing: Product Life Cycles, Allocation Rules, and Cost Models. In Proceedings of DETC'04 ASME 2004 Design Engineering Technical Conferences and Computers and Information in Engineering Conference, pp: 857 - 868, September 28 - October 2, 2004, Salt Lake City, Utah, USA.

Govil, M. K., and E.B. Magrab. 2000. Incorporating Production Concerns in Conceptual Product Design. International Journal of Product Design, 2000, Vol. 38, No. 16, pp: 3823 - 3843

Hackett, E. A. 1983. Application of a Set of Learning Curve Models to Repetitive Tasks. The Radio and Electronic Engineer, IERE, January 1983, Vol. 53, No. 1, pp: 25 - 32 


\section{Altuger and Chassapis}

Jaber, M. Y., and M. Bonney. 1996. Production Breaks and the Learning Curve: The Forgetting Phenomenon. Applied Mathematical Modeling, February 1996, Vol. 20, pp: 162 - 169

Mc Lean, C., and G. Shao. 2003. Generic Case Studies for Manufacturing Simulation Applications, In Proceedings of the 2003 Winter Simulation Conference, ed. S. Chick, P. J. Sanchez, D. Ferrin, and D. J. Morrice, 1217-1224. Piscataway, New Jersey: Institute of Electrical and Electronics Engineers, Inc.

National Aeronautics and Space Association, NASA, 2007. Learning Curve Calculator and Cost Estimation, http://cost.jsc.nasa.gov/learn.html

Seppanen, M. S. 2005. Operator - Paced Assembly Line Simulation. In Proceedings of the 2005 Winter Simulation Conference, ed. M. E. Kuhl, N. M. Steiger, F. B. Armstrong, and J. A. Joines, 1343-1349. Piscataway, New Jersey: Institute of Electrical and Electronics Engineers, Inc.

Shafer, S. M., D.A. Nembhard, and M.V. Uzumeri. 2001. The Effects of Worker Learning, Forgetting, and Heterogeneity on Assembly Line Productivity. Management Science, December 2001, Vol. 47., No. 12, pp: 1639 - 1653

TPub Integrated Publishing, Electrical Engineering Training Series , Updated on 04/10/2010. http://www.tpub.com/content/neets/14175/css/14175_107.htm

Venkateswaran, J., Y-J. Son, and A. Jones. 2004. Hierarchical Production Planning Using A Hybrid System Dynamic - Discrete Event Simulation Architecture. In Proceedings of the 2004 Winter Simulation Conference, ed. R. G. Ingalls, M. D. Rossetti, J. S. Smith, and B. A. Peters, 1094 - 1102. Piscataway, New Jersey: Institute of Electrical and Electronics Engineers, Inc.

Yang, Z., Q. Chang, D. Djurdjanovic, J. Ni, and J. Lee. 2007. Maintenance Priority Assignment Utilizing On - Line Production Information. Journal of Manufacturing Science and Engineering, April 2007, Vol. 129, pp: 435 - 446

\section{AUTHOR BIOGRAPHIES}

GONCA ALTUGER is currently a Ph.D. Candidate in the Mechanical Engineering Department at Stevens Institute of Technology. She received an undergraduate degree in Mechanical Engineering from EOU Turkey and a Master's degree in Mechanical Engineering from Stevens Institute of Technology. Her research focus is on knowledge-based intelligent design and production systems. Her email is <galtuger@stevens.edu >.

CONSTANTIN CHASSAPIS is a Deputy Dean of the School of Engineering and Science, Department Director and Professor in the Mechanical Engineering Department at Stevens Institute of Technology. His research interests are in knowledge-based engineering systems, computer-aided design and manufacturing, as well as in remotely controlled distributed systems. He has been an active member in ASME, and he has received best paper awards from SPE's Injection Molding Division and ASEE, the distinguished Assistant Professor Award at Stevens Institute of Technology, an Honorary Master's Degree from Stevens Institute of Technology, and the Tau Beta Pi Academic Excellence Award. His email is $<$ cchassap@stevens.edu>. 